\title{
Artificial Land Concepts and the Architecture of Megastructure in Seoul
}

\author{
Dario Pedrabissi \\ University of Portsmouth/School of Architecture, Portsmouth, United Kingdom \\ Email: dario.pedrabissi@port.ac.uk
}

\begin{abstract}
In this paper, I discuss the main arguments that deal with the issue of high density and utopian architectural projects to investigate the advance of megastructure buildings and artificial land concepts in Seoul during the 1960-70s. It is my purpose to highlight the architectural influences that have generated these ideas by pointing to the genesis and the evolution of critical projects in Seoul.

The paper is structured as follows. After giving an overview of the scope of the contemporary high-density urban factors, I review the particular evolution of the megastructure projects from the 1950s. This analysis creates the background to introduce South Korean projects that have been influenced by the international concepts of utopia. The main case study is the Sewoon Sangga building and its strictly related synergy with the highly productive surrounding area.

The results of this research have advanced the ground for further investigations on the evolution of megastructure projects and their influence on the surrounding urban environment. The clash between formal and informal architecture is particularly accentuated in Seoul as the highdensity condition of this megacity generates situations that reflect both the traditional milieu and the technologically advanced environment.
\end{abstract}

Index Terms - urban density, megastructure, artificial land, megacity, utopia, informality.

\section{INTRODUCTION}

Urban density is a topic widely studied, and yet is a very contemporary issue that needs to be further explored in order to envision the future of our cities. The urbanisation process that started with the Industrial Revolution is still ongoing and is expected to increase its impact, producing newer and larger megacities. The main change is its focus, as now East Asian, and in the future, Indian and African countries will host the largest megacities in the world.

In fact, in 2030, Delhi will be the world largest city with 38.9 million people, surpassing Tokyo which will start to see a decrease in its population [1] due to demographic changes and political decisions. China is advancing with new administrative processes and urban strategies to cope with the predicted increase in its urban population, which will reach 1 billion people by 2030 [1]. An example is the plan to combine three existing cities, Beijing, Tianjin and Hebei, into a supercity of 130 million people, creating a giant urban hub [2]. In South Korea, Seoul experienced unprecedented country-to-city migration after the Korean War (1950-53). The so-called economic "miracle of the Hangang river" exploded, and starting in the early 1960s, Seoul underwent exponential demographic growth [3]. Nowadays, Seoul Capital Area is an urban agglomeration that comprises 24 million people and combines both hyper-technological urban systems with a strong traditional character.

In this context, urban planning needs to be advanced at a regional level, involving numerous stakeholders guided by forward-thinking political decisions. Architects have been at the forefront of this process, designing and building projects that responded to the issue of increasing density in the modern city. Starting in the 1920s, when the housing shortage became a pervasive problem, architects have advanced solutions that involved standardisation and prefabrication in minimising construction costs and in maximising the quantity of built housing units [4].

After the Second World War, an unprecedented urban expansion occurred, and new international concepts of utopia were tested [5]. Among these, the Metabolists in Japan was the most prolific and organised group, advancing with an avant-garde design that dealt with the high-density condition of Tokyo, a result of the limits set by the mountainous topography of the countryside. This limitation culminated in the design concepts that embodied the idea of "artificial land", envisioned as structures superimposed on the natural ground and suspended on platforms or pilotis, although still in close relationship with the original topography [6]. This idea has largely influenced the design of megastructure projects around the world, including in South Korea, and therefore, it is crucial to define the evolution of the megastructure buildings.

\section{The ARChitecture OF THE MegastruCtures}

The megastructure projects dominated the progressive concept of architecture and urbanism around the world from the late 1950s to the early 1970s. Among the most important contributions, we find the work of the Japanese Metabolists, the radical visions of the Archigram group in London, and the Superstudio and Archizoom in Florence, that have advanced in a more visionary way the utopian concept of artificial land. 
The definition of megastructures is not straightforward not all large buildings can be defined as such. Their dimensions are undeniably one of the features that characterise them, although a multitude of aspects and concepts defines megastructure buildings. Reyner Banham, in his analysis on the megastructure [7] tries to define this type of building by identifying the most critical ancestor with the Le Corbusier's Fort l'Empereur project from his Algiers plan of 1931, Fig. 1. In the wellrenowned drawing, the large supporting structure is simple and has the mere function of allowing the unplanned construction of accommodation units which are represented in a variety of styles embodying individual tastes.

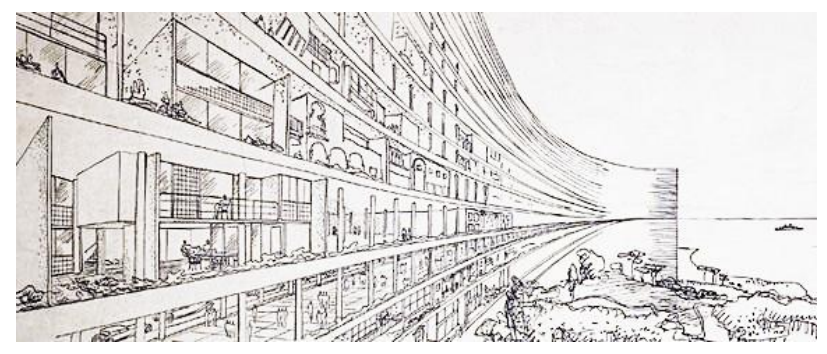

Figure 1. Project 'A', Fort L'Empereur, Algiers, Le Corbusier, 1931. Source: Fondation Le Corbusier

Banham analyses the definition given by Fumihiko Maki in his Investigation in Collective Form of 1964, where he defines the megastructure as a "large frame in which all the functions of a city or part of a city are housed. It has been made possible by present-day technology. In a sense, it is a man-made feature of the landscape. It is like the great hill on which the Italian town was built...". He also emphasises the "rapidlychanging functional units which fit within the larger framework" thus stressing the large, almost monumental structure and the ephemeral and interchangeable habitable units, which together seem to form the consolidated features of the megastructure. Kisho Kurokawa in the Wall City project proposes to integrate all of the city's functions into an endless grid of walls that also incorporate high-speed mobility systems and plug-in housing units Fig. 2.

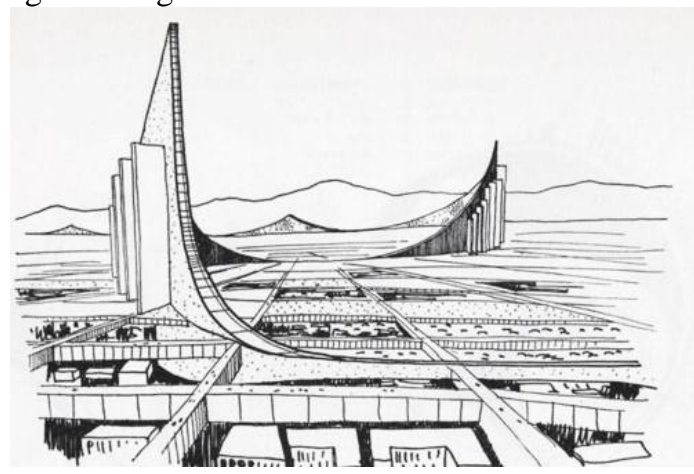

Figure 2. Wall City, Kisho Kurokawa, Japan, 1959. Source: Project Japan: metabolism talks... Taschen Cologne, 2011

Similarly, in 1961 the Dutch architect Nicholas Habraken developed the idea of support and infill, adding an important social factor to the concept [8]. In his vision, the support was seen again as the large, virtually permanent, structure that would have allowed the infill of the lighter, almost ephemeral, constructions within the heavy support. The main novelty in Habraken's idea is the involvement of the city dwellers in the design process of their house. Thus, the architect would have independently decided the design of the supporting structure, while he would have designed the infills with the help of the citizens.

These initial ideas can be seen as the precursors of a stream of projects built around the world, that have identified the artificial land concepts as a leading idea to tackle with the density problem. The scheme had the potential, in the view of the architects, to deal with the constant need for flexibility that was necessary for the modern city.

\section{SEOUL'S URBAN TRANSFORMATION AND ARTIFICIAL LAND CONCEPTS}

In Seoul, the scarcity of land and the constant immigration of people from the countryside forced architects and planners to advance with new urban strategies.

\section{A. Seoul Urban Transformation}

This fast urbanisation process required an integrated urban plan to guide the transformation. Initially, the proposed urban model was inspired by the Western NewTown Planning and Garden City ideas. Thus, Seoul adopted an urban growth organisation strategy based on ring-radial roadway circulation, multiple centres, and green belts. The resulting 1966 Comprehensive Development Plan was put into place to facilitate the expansion of the city, proposing four ring roads at varying distances from the city centre and thirteen radial arterials, creating intersections that were to become subcentres [9]. This plan was followed by the 1972 National Development Plan, which introduced a new greenbelt system, easily omitted by unplanned development. The plan also pushed new development towards the south side of the Han River and, by the mid1980s, the expanse of urbanisation on both the north and south banks of the river was equal [9].

From 1961-87 South Korea was ruled by a military dictatorship, and during the leadership of President Park Chung-Hee (1961-79), the modernisation process was especially key to the political agenda. This period was characterised by massive economic growth coupled with severe repression. President Park had the clear intention to use urban transformation as a tool for social reform, introducing large scale population control in Seoul. Thus, the construction of vast mass housing projects was seen as "a very powerful tool for guiding and managing the social groups that have been at the core of South Korea's economic development" [10].

From the 1960s, the majority of the new housing projects in Seoul were developed in the form of massive housing complexes called tanji, formed by collective housings, at least 300 units, autonomy, and shared facilities [10]. The tanji is defined as a grouping of large 
urban blocks, containing monofunctional residential slabs, interspersed with small commercial buildings and service facilities [11]. This typology proliferated during the 1970-80s across the whole of South Korea and formed its distinctive massive display of modern apartment buildings.

\section{B. Utopian Projects}

To advance with key utopian projects for the transformation of Seoul, the government established the Korea Engineering Consultants Corporation (KECC) in 1965. Representative architects gathered in this institutional body at the end of the 1960s to speculate on bold, large-scale and state-backed projects [12]. Kim Swoo Geun, the most renowned Korean architect of the time, merged his office with the KECC for three years (1966-69) and built one of the most iconic megastructure projects in Seoul, the Sewoon Sangga complex, Fig. 3, in the very heart of the city, and planned the Yeouido Master Plan along the Han River. These two paradigmatic projects - the first built according to his plan, while the second drastically altered from the original proposal incorporated the concept of artificial land, seen as an opportunity to create a new urban order.

Sewoon Sangga is the most famous megastructure project constructed in Seoul which embodies all of the main characters of the modernist utopia. It spans from Jongmyo, in the north, to Namsan in the south, and is composed of four blocks interconnected by an elevated pedestrian deck level on the third floor. This constitutes the actual artificial land, forming a one-kilometre-long building. The complex initially contained commercial facilities up to the fourth floor and residential units on the upper stories. Sewoon Sangga was acclaimed for its innovative hybrid composition of functions, although it lost its fame shortly afterwards, in favour of the newly constructed neighbourhoods on the southern side of the Han River that flourished from the 1970s.

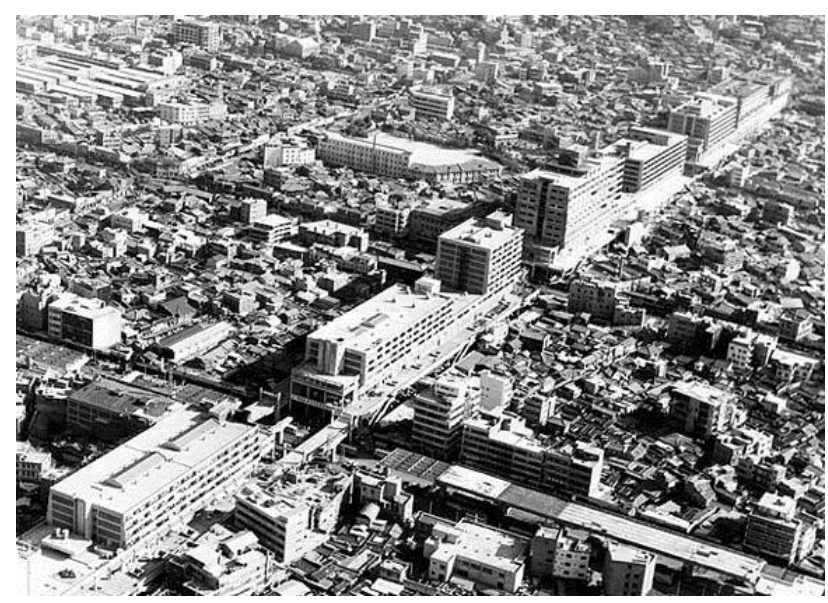

Figure 3. Sewoon Sangga, Seoul, 1968. Source: National Archives of Korea

Problems of land ownership were crucial for the realisation of the project. The area - once clear from any construction to prevent the propagation of fire during the war period - had been occupied by informal settlements from 1953. Furthermore, part of the land was publicly owned, while the rest was privately owned. The state's developmental plan found a strategy to enable investments on projects to further the purpose of Seoul's progress, involving construction companies and landowner unions in the process [13]. Although on a much smaller scale, Nakwon Musical Instrument Arcade is another example of a building conceived as artificial land, built on top of a four-lane road in proximity to the Insa-dong area. The new land strategy took into account the problems that this earlier project has produced refining the financial and legal agreements among the different stakeholders.

\section{The Contemporary Condition of Sewoon Sangga and Its Surrounding Area}

Nowadays, Sewoon Complex, with its surrounding eight large urban blocks, forms a manufacturing hub mainly focused on electrical and electronic products. Other activities comprise metal works and printing firms forming an exceptional community of highly skilled workers. This unique, almost medieval productive centre is located in the very heart of the city, surrounded by expensive office buildings and a Royal Palace. Consequently, the whole area is now under tremendous pressure and, especially after the Cheonggyecheon river renovation, this productive ecosystem has become prime real estate. Several large urban projects were proposed in the last twenty years, always involving the destruction of the existing buildings and the relocation of the local craftspeople.

In 2009 the government also proposed to demolish Sewoon Sangga building and to transform it into a linear park, allowing the construction of tall office buildings in its surroundings. Fortunately, the whole plan has been abandoned due to massive protests from the local workers and citizens [14]. In 2017, the elevated deck of Sewoon Sangga was restored, and new pedestrian bridges were constructed to connect the different buildings' blocks.

Nowadays the residential units on the upper level of Sewoon Sangga have been mainly transformed to office spaces that accommodate small businesses. The new creative occupation of Sewoon Sangga, has contributed to strengthening the synergy with the surrounding area. Start-up companies, design firms, and global networks as the Fab Lab Seoul, have created a unique environment which perfectly integrates with the productive hub that surrounds the building. Here, an extensive network of small-scale factories and shops provide a fast and resilient productive system that spans from the electrical and electronic shops, the metal factories that extend their production line on the streets, and the printing factories with their incessant, repetitive noise that pervade the streets. The whole neighbourhood is a highly dynamic ecosystem that is extremely rare to witness in a modern megacity, dominated by business districts.

The Sewoon Sangga building is the typical product of the modernist avant-garde. Kim Swoo Geun has conceived this project reflecting on the Metabolist concept of a megastructure that could accommodate further changes Fig. 4. 
te?

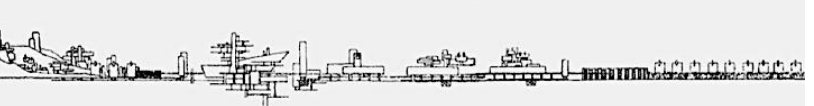

Figure 4. Sketch section. Initial concept of Sewoon Sangga. From SPACE 1967.09

The result was instead a very rigid composition of volumes that paradoxically were able to be transformed and reinterpreted throughout the years. The everchanging surrounding area, with its medley composition of the urban program, has instead conquered the Sewoon Sangga, imposing its program and creating a productive system in the very heart of Seoul, Fig. 5 and 6. This ecosystem is now studied by many urban planners, sociologist and policy-makers. Although this area is still under threat by the existing urban code and guidelines, which allows for $600 \%$ of floor area ration, with no clear definition of detailed guidelines for the big blocks [15]. This uncertainty is allowing the transformation of large sections of the area, imposing large blocks and tall buildings, creating a further clash with the existing urban fabric.

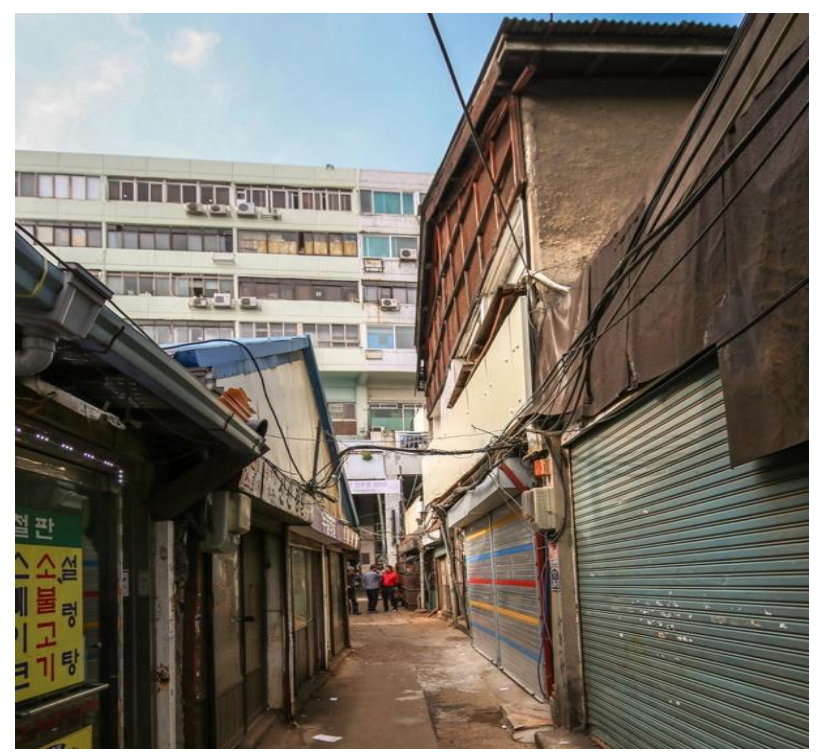

Figure 5. Picture of the surrounding area in the proximity of Sewoon Sangga (in the background). Source: the author.

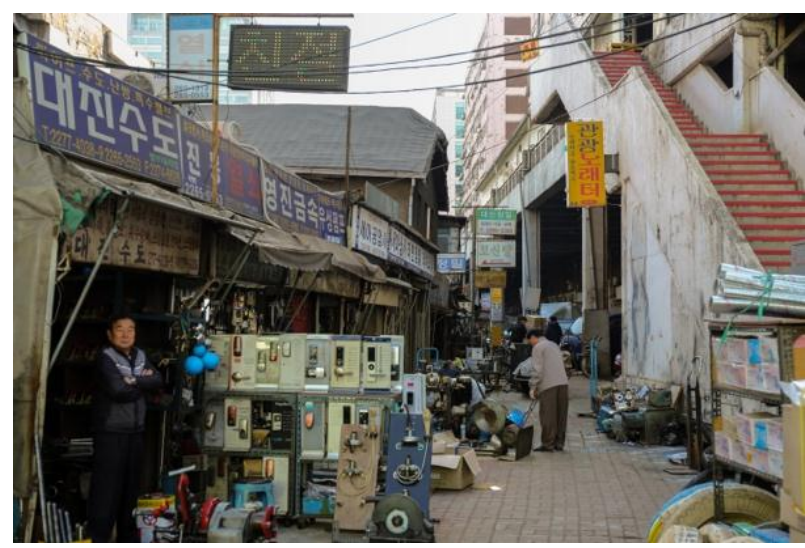

Figure 6. Pictures of the surrounding area in the proximity of Sewoon Sangga (on the right) Source: the author.

\section{FINAL REMARKS}

This contribution is structured in three main sections that aim to underline the influences that have generated the main megastructure projects in Seoul. The first introductory part deals with the density issues that Seoul - alongside with a rising number of new world megacities - is facing. Urban density is becoming more extreme, and the urge to accommodate the ever-increasing urban population is forcing architects and planners to develop new solutions. Thus, it is essential to study the legacy of the first visionary ideas that were inspired by density factors.

The second part introduces the international concepts of utopia and the megastructure projects that were generated in Europe and Japan in the early 1960s. The third part presents the work of Kim Swoo Geun and the Sewoon Sangga building. Other projects are introduced concerning the problem of land ownership, as well as the unrealised utopia of the Yeouido Master Plan.

An important factor that emerges in the study of the Sewoon Sangga complex is the constant re-adaptation of its spaces and its strong relationship with the surrounding area. This unique manufacturing environment is composed of an organic settlement of small buildings organised on the original urban pattern of the ancient city. The contrast between this convoluted pattern of low-rise buildings and the straight and imposing Sewoon Sangga megastructure building is striking, although the capillarity, besides the great variety of shops and productive workshops that are present in both places, is the bond of this exceptional environment.

In this regard, further research on this topic would contribute to the analysis of informality in architecture in relationship to megastructure projects and their influences on the surrounding neighbourhoods.

\section{CONFLICT OF INTEREST}

The authors declare no conflict of interest.

\section{AUTHOR CONTRIBUTIONS}

Dario Pedrabissi is the only author of this conference paper. He has conducted both primary and secondary research on the topic, and he is responsible for the entire development of the paper.

\section{ACKNOWLEDGEMENT}

This work was supported in part by a grant from the Faculty of Creative and Cultural Industries, School of Architecture, University of Portsmouth, United Kingdom.

\section{REFERENCES}

[1] "The World's Cities in 2018," 2018.

[2] "How megacities compare: China plans a city 25 times the size of London | Cities | The Guardian." [Online]. Available: https://www.theguardian.com/cities/shortcuts/2015/jul/26/jing-jinji-chinese-megacity-25-times-size-of-london. [Accessed: 28-Apr2019].

[3] Y. W. Kim, "Industrialisation and urbanisation in Korea," Korea J., vol. 39, no. 3, pp. 35-62, 1999. 
[4] P. Hall, Cities of Tomorrow: An Intellectual History of Urban Planning and Design Since 1880. John Wiley \& Sons, 2014.

[5] M. Tafuri and F. D. Co, Modern Architecture. Electa/Rizzoli, 1987.

[6] R. Koolhaas, H. U. Obrist, K. Ota, J. Westcott, and T. Daniell, Project Japan: Metabolism Talks. Taschen Cologne, 2011.

[7] R. Banham, Megastructure: Urban Futures of the Recent Past, London: Thames and Hudson, 1976.

[8] N. J. Habraken and J. Teicher, The Structure of the Ordinary: Form and Control in the Built Environment, MIT Press, 2000.

[9] P. G. Rowe, East Asia Modern: Shaping the Contemporary City, London: Reaktion books, 2005.

[10] V. Gelézeau, "Korean modernism, modern Korean cityscapes, and mass housing development: charting the rise of Ap'at'ŭ Tanji since the 1969s," in Korea Yearbook 2007, Politics, Economy, and Society, Rüdiger Frank et al., Ed. Leiden \& Boston: Brill, 2007.

[11] D. Pedrabissi, "Modern housing complexes in South Korea," in AMPS Proceedings Series 7, 2016

[12] J. Park, S. Kim, J. M. Shim, and S. Park, Eds., Spectres of the State Avant-Garde. Mapo-gu: Propaganda Press, 2018.

[13] N. Kang, "Sewoon sangga and megastructure," in Spectre of the State Avant-Garde, J. Park, S. Jim, J. M. Shim, S. Park, and A. S. Kim, Eds. Propaganda Press, 2018, pp. 63-78.

[14] J. Kim and B. De Meulder, "A modernist utopia taken over by the ordinary. The consecutive lives of the seun complex in Seoul, South Kora.," Éditions la Fac. d'Architecture La Cambre Horta l'Université Libr. Bruxelles, vol. 1, no. 4, pp. 85-102, 2017.

[15] S. Kim, "The ecosystem of industries in downtown seoul and the implication of large-scale projects," in Seun Sangga Kü Isang: Taekyumo Kyehoek Nŏmó [Beyond Seun Sangga: 16 ideas to go Beyond Big Plans], V. Kang and H. Park, Eds. Konggan Sŏga, 2015, pp. 18-33.

Copyright (C) 2020 by the authors. This is an open access article distributed under the Creative Commons Attribution License (CC BYNC-ND 4.0), which permits use, distribution and reproduction in any medium, provided that the article is properly cited, the use is noncommercial and no modifications or adaptations are made.
Dario Pedrabissi is a practising architect, researcher and educator, working in the fields of architecture, interiors, public spaces, and installations. He was born in Cremona, Italy, in 1979 and received his MSc in architecture and the built environment from the University of Technology, Delft, the Netherlands, and a BSc in architecture from the University of Florence in Italy.

$\mathrm{He}$ is currently Lecturer at the School of Architecture, University of Portsmouth, U.K. Prior to this, Mr Pedrabissi was Assistant Professor at Korea Tech (South Korea) for six years, and worked for several local practices in Italy - both in design and construction - and was involved in public and private projects on different scales for five years. In 2014, he founded Pedrabissi Studio in South Korea, a young design practice which operates to expand the disciplinary boundary of architecture into the fields of visual arts, material exploration and historical research. The studio's interest lies in diverse fields ranging from architectural design to urban research and the creation of public artworks: http://www.pedrabissi.eu/. His latest publications are Pedrabissi Dario. "Seoul urban shift. The transformation of obsolete infrastructure into linear parks." In Disruptive Technologies. The integration of advanced technology in architecture teaching and radical projects for the future city. Edited by Auer Thomas, Melis Alessandro, Aimar Fabrizio, chap. 8. Wolters Kluwer Italia, 2017. Pedrabissi, Dario. "Modern Housing Complexes in South Korea. Typological Evolution and Urban Adaptations". In AMPS Extended Proceedings: Future Housing: Global Cities and Regional Problems. Swinburne University of Technology, Melbourne, Australia, June 9-10, 2016. Pedrabissi, Dario. "Public Art on University Campuses. How Art Engages with the Public Space". In KSDS and ADADA with Cumulus Proceedings: 2015 International Design Congress. Chonnam National University, Gwangju, South Korea, October 17-23, 2015.

Mr Pedrabissi is a registered architect in the U.K. (A.R.B.), Italy (O.A.P.P.C.) and The Netherlands (S.B.A.). Furthermore, he is a Fellow at the Higher Education Academy (FHEA) in the U.K. He served as a jury member for Asia and the Pacific for the UN-Habitat Urban Revitalization of Mass Housing Design Competition. 